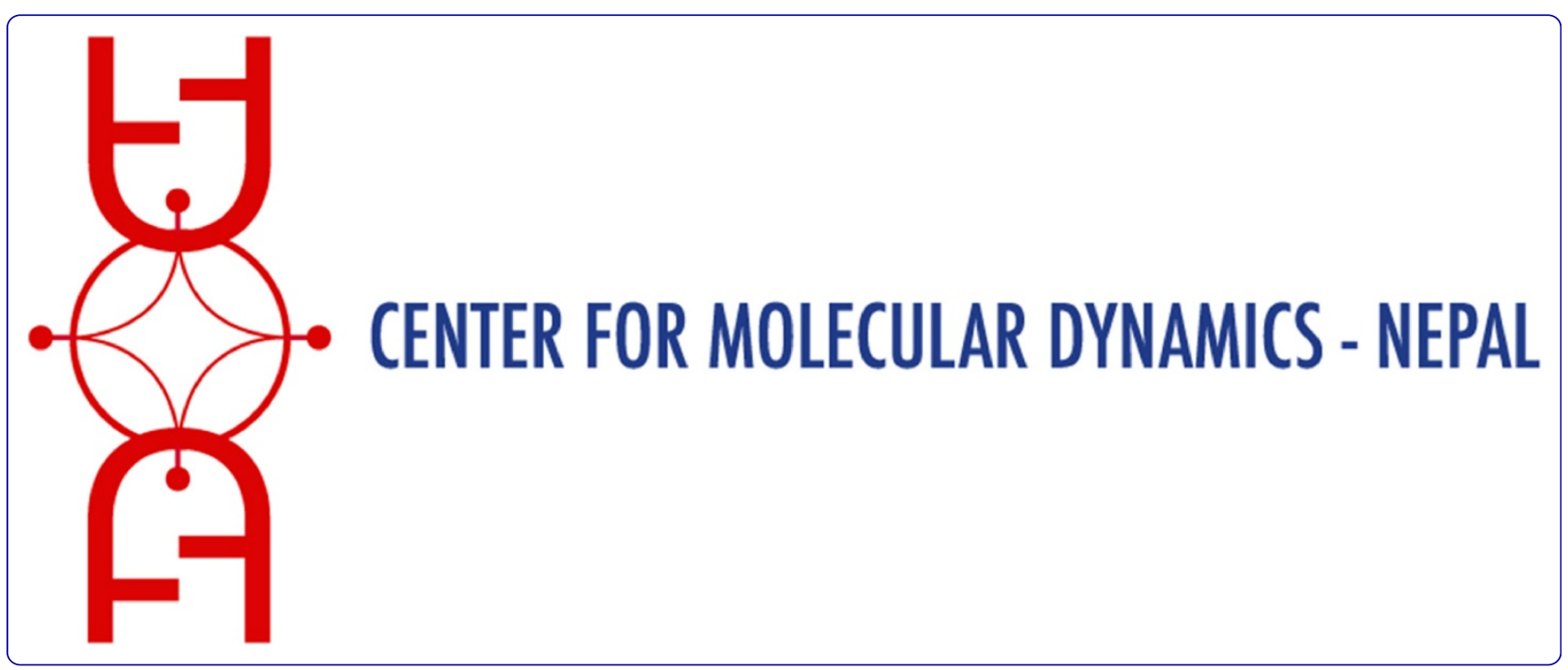

A study on relapse/re-infection rate of Plasmodium vivax malaria and identification of the predominant genotypes of $P$. vivax in two endemic districts of Nepal

Manandhar et al. 


\title{
A study on relapse/re-infection rate of Plasmodium vivax malaria and identification of the predominant genotypes of $P$. vivax in two endemic districts of Nepal
}

\author{
Sulochana Manandhar ${ }^{1}$, Chop L Bhusal ${ }^{2}$, Umesh Ghimire², Shankar P Singh², Dibesh B Karmacharya \\ and Sameer M Dixit ${ }^{1 *}$
}

\begin{abstract}
Background: Malaria is a major public health problem in Nepal inflicted primarily by the parasite Plasmodium vivax, the only species responsible for relapse cases in Nepal. Knowledge on its relapse rate is important for successful malaria control, but is lacking in Nepal. The information on circulating predominant genotypes of $P$. vivax is equally relevant for high endemic districts of Nepal to understand the transmission dynamics of the parasite and to uncover the coverage and efficacy of potential vaccine beforehand.

Methods: A prospective observational study with a six months follow-up period was conducted from August 2010 to May 2011 in four health centres of Kailali and Kanchanpur districts of Nepal to access the relapse/re-infection rate of $P$. vivax. The prevalence and heterogeneity of its genotypes were identified by PCR-RFLP assay targeting central repeat region of circumsporozoite protein (Pvcsp).
\end{abstract}

Results: In total, 137 cases microscopically suspected to have $P$. vivax infection were enrolled in the study. Of these, 23 cases (17\%) were detected for the relapse/ re-infection-during a six-month period, with a high proportion being male cases of age group 11-20 years. For genotyping, 100 whole blood samples were analysed, of which $95 \%$ of the parasite isolates were found to be of VK210 genotype. The minor genotype VK247 existed either in isolation or as mixed infection with VK210 in rest of the samples.

Conclusions: The relapse/re-infection rate of $17 \%$ was determined for $P$. vivax in Kailali and Kanchanpur districts of Nepal. A heterogeneous Pvcsp genotypic distribution of P. vivax was detected with VK210 being a predominant type, suggesting a complex transmission dynamics of the parasite. Expanding such study in other endemic regions of Nepal would help provide a complete picture on relapse/re-infection rate and parasite genotypic variability that can help in effective control and management of malaria in Nepal.

Keywords: Plasmodium vivax, Circumsporozoite protein, Genotypes, Relapse/reinfection rate, Nepal

\section{Background}

In Nepal, 22.5 million people still live in malaria-prone areas with 65 of 75 districts considered endemic to the disease [1]. Malaria control has been identified as priority-I public health programme of Nepal under the National Health Sector Programme Implementation Plan-II (NHSP-II)

\footnotetext{
*Correspondence: s.dixit@cmdn.org

${ }^{1}$ Center for Molecular Dynamics Nepal, 5th Floor Swaraj Sadan, Prasuti Griha Marg, Thapathali-11, Kathmandu, Nepal

Full list of author information is available at the end of the article
}

2010-2015 [2]. In Nepal, Plasmodium vivax is responsible for most of disease burden, with 75 to $80 \%$ of reported malaria cases being accounted by this species of the parasite [2]. It is also the only species in Nepal responsible for leading to relapses. It is co-endemic with Plasmodium falciparum in high-endemic districts [1]. Since mortality due to $P$. vivax is lower compared to $P$. falciparum, the former species has been relatively neglected and, therefore, largely under-researched [3]. Controlling vector-borne diseases, such as malaria, is a challenge for 
economically-weak countries like Nepal. Further, the possibility of relapse infections exhibited in the cases of $P$. vivax is a barrier to successful treatment and control of malaria. Thus, determining relapse pattern is an indispensible component for early management of vivax malaria.

The neighbouring cities of Indian states are not only the hub of employment for Nepalis, especially those residing near the border, but are also the source of infectious diseases. A significant proportion of malaria in the eastern region of Nepal and all other bordering districts is considered to be imported from border cities of India [4]. Since malarial epidemiology varies considerably between different geographic regions as a result of complex interplay among humans and vectors, such porous borders impose a significant contribution in affecting the genetic complexity of the parasite. The knowledge on genotypes of malarial parasites contributes greatly to our understanding of the dynamics of disease transmission because studies have shown probable difference in the choice of preferred Anopheles species as a vector by various genotypes of $P$. vivax [5]. Genotyping of $P$. vivax species can also help differentiate between a new infection and a relapsed one, which can play an important role in controlling the disease [6]. Since several antigens expressed on the surface of the parasite or on infected human blood or liver cells strongly illicit the host immune system, any genetic polymorphisms in these antigens play a critical role in evading protective immune responses thereby hindering the development of an effective vaccine against any Plasmodium species [7]. Thus, understanding the genetic diversity of potent surface antigens of $P$. vivax from various endemic geographic regions across the world is important in providing crucial data for development of an effective vaccine [8].

Circumsporozoite protein $(P v c s p)$ is an abundant surface antigen of $P$. vivax sporozoites. The gene encoding this protein contains a central region composed of one of the two types of nona-peptide repeat units, based on which, the parasite has been divided into two genotypic variants. The variants with one of the repeat units GDRA(A/D)GQPA, that is restriction digested by the enzyme AluI is referred to as VK210 genotype while those with the other repeat unit ANGA(G/D)(N/ D)QPG, that is restricted by BstNI is recognized as VK247 type [9-12]. Studies have showed differential geographical distribution and probable differences in transmission intensity, vector selection, drug resistance and treatment responses existing in these genotypes [13-16].

Since no Pvcsp-based genotyping studies have been carried out before in Nepal, this study aims to provide a pilot data on Pvcsp genotypes circulating in Kailali and Kanchanpur districts for Nepal.

\section{Methods}

\section{Relapse/re-infection study}

A prospective observational study was carried out in four health centres of Kailali and Kanchanpur districts of far-west Nepal from August 2010 to May 2011. These districts are among high malaria endemic districts of Nepal. As per the 2010 annual report of Department of Health Services, Government of Nepal, the annual parasite incidence rate per 1,000 population was $1.77 \%$ for Kailali and $0.6 \%$ for Kanchanpur, while that for the entire nation was just $0.16 \%$ in the year 2010 .

After taking an informed consent from malariasuspected symptomatic patients and performing their initial clinical examination, the blood samples were collected for thick blood film microscopic examination. The parasitological examination was done independently by two trained laboratory technicians and the slides were sent to an independent laboratory for quality assurance. All febrile patients positive for $P$. vivax in microscopy at the time of visit and confirming to be able to come on stipulated follow-up visits were considered eligible and were enrolled in the study. Any of the cases failing to show the microscopic evidence of $P$. vivax or showing mixed or isolated infection with $P$. falciparum or presenting any feature of severe malaria or any other underlying chronic severe illness were excluded from the study. Pregnant women and lactating mothers were also excluded from the study.

The $P$. vivax-confirmed enrolled cases were asked to complete the three-day $25 \mathrm{mg} / \mathrm{kg}$ body weight of chloroquine therapy. The national anti-malarial treatment guidelines of Nepal suggested the combined use of three-day chloroquine and 14-day primaquine for all $P$. vivax confirmed cases. However, the actual trend practiced in the selected study area was to provide chloroquine monotherapy to all cases of clinical and $P$. vivax malaria. The chloroquine-primaquine therapy was administered only in the cases who returned to the centre with renewed symptoms of malaria and further microscopic evidence of $P$. vivax.

The first dosage of chloroquine was administered under direct observation of the research team on the day when the participant was first enrolled in the study. The second and third dosages were prescribed for home use with a detail instruction on the drug regimen and follow up and with a proper education on the importance of doing so.

The cases were advised to come for follow-up visits on the third day and at the sixth month of enrolment or on any day/s when the patient felt febrile. The cases were rigorously reminded for follow up visits by regular telephone calls. When required, home visits were also done by the trained and locally mobilized community field team. An absolute treatment compliance was assumed 
to have achieved if the cases succeeded to appear in all stipulated follow up days.

Because the selected study areas had high $P$. vivax incidence rate, the chances of re-infection at any point after the completion of chloroquine therapy could not be ignored. Thus, all recurrences were assumed to be either because of relapses or re-infections. And because the study areas had rare history of treatment failure for $P$. vivax chloroquine therapy, the recrudescence was assumed to be unlikely.

Due to the logistical and financial constrains, the cases could be followed up for a period of six months only. On each follow-up day, thick blood film examination was carried out. Those febrile patients who returned the centre after one month of the start of chloroquine therapy and were microscopically found to be positive for $P$. vivax were considered relapse/re-infection cases whose rate was determined by dividing the number of such recurred cases by total number of $P$. vivax confirmed cases treated with standard chloroquine regimen. The cases presenting with recurrences and the remainder of enrolled cases who completed six months of follow up were given primaquine therapy in the dosage of $7.5 \mathrm{mg}$ twice a day for 14 days after screening for G6PD deficiency.

\section{Genotyping study}

Parasite DNA was extracted from whole blood samples using commercial DNA extraction kit (QiagenDNeasy Blood \& Tissue Kit). Before processing for genotyping assay, all microscopically detected samples were confirmed for the presence of $P$. vivax by two rounds of nested PCR targeting ssrRNA [17]. Plasmodium vivax confirmed samples were genotyped by nested PCR-RFLP assay based on central repeat region of Pvcsp gene as mentioned by Imwong et al. [18]. Briefly PCR reaction was set with $800 \mathrm{nM}$ dNTPs, $1 \mathrm{mM} \mathrm{MgCl} 2$, 0.4 unit Taq polymerase, $400 \mathrm{nM}$ of each primers with $1 \mu \mathrm{l}$ of DNA template for first round and $1 \mu \mathrm{l}$ of first round PCR product as template for second round nested PCR. The thermocycling condition for first round PCR was $95^{\circ} \mathrm{C}$ for $5 \mathrm{~min}$ followed by 25 cycles of $58^{\circ} \mathrm{C}$ for $2 \mathrm{~min}, 72^{\circ} \mathrm{C}$ for $2 \mathrm{~min}$ and $94^{\circ} \mathrm{C}$ for $1 \mathrm{~min}$, and one cycle of each $58^{\circ} \mathrm{C}$ for $2 \mathrm{~min}$ and $72^{\circ} \mathrm{C}$ for $5 \mathrm{~min}$. That for second nested PCR was exactly the same as for first round except that annealing was at $62^{\circ} \mathrm{C}$ for 2 min and with 30 cycles. The second round products were digested by restriction enzymes $A l u \mathrm{I}$ and $B s t N I$ in parallel set of tubes and visualized in $2 \%$ agarose gel to distinguish between two genotypes of $P$. vivax on the basis of susceptibility to digestion by any one of the enzymes. Broader Pvcsp genotypes of $P$. vivax isolates were further attempted to subdivide into finer Pvcsp allelic types utilizing fragment size heterogeneity of PCR products and sequence variations in pre- and post-repeat regions by PCR-RFLP protocol followed by $3 \%$ agarose gel electrophoresis as mentioned by Imwong et al. [18].

\section{Ethical approval}

This study was initiated by Nepal Health Research Council (NHRC), with documented approval from its Ethical Review Board (ERB).

\section{Results}

\section{Relapse/re-infection assessment}

Among malaria-suspected patients visiting four selected health centres, a total of 137 cases were microscopically observed for $P$. vivax infection and fulfilled other inclusion criteria. Age distribution of these cases varied from 15 to 83 years. The highest percentage of cases affected belonged to the productive age group of 21 to 30 years (35.7\%) followed by 11 to 20 years (27\%) (Figure 1 ). The number of male cases affected was much higher (81\%) than that of female cases. Out of 137 total cases enrolled, recurrence was reported among 23 cases (17\%). A high percentage $(47.8 \%)$ of relapse/re-infection occurred among young people of age group of 11 to 20 years (Figure 1) and among male patients (91.3\%). However this recurrence rate difference by gender could not be considered significant because the initial number of male cases studied was much greater than that of female cases.

All of the 23 cases of the first reported recurrences occurred after one month of primary detection of the parasite. During a six-month follow-up period, most (56.56\%) recurrences were reported only once. The remainder of the recurrences were reported for multiple number of times ranging from twice to five times despite the possible completion of 14-day unobserved primaquine therapy.

\section{Genotype assessment}

Molecular analysis could be carried out in only 100 randomly selected blood samples. All of these samples were positive for $P$. vivax in two separate rounds of nested PCR. Among all samples tested, 95\% of $P$. vivax parasites were found to be of VK210 genotype in PCR-RFLP based Pvcsp molecular genotyping assay. The remainder (5\%) of the isolates belonged to VK247 type, 40\% of which existed as mixed infection with VK210. Figure 2 shows representative agarose gel image of restriction digestion of Pvcsp gene for genotyping test.

Allelic variations of each VK210 and VK247 isolates could not be distinguished either based on fragment size variation of PCR products or PCR-RFLP based sequence variation of pre and post repeat regions when analysed in $3 \%$ agarose gel. 


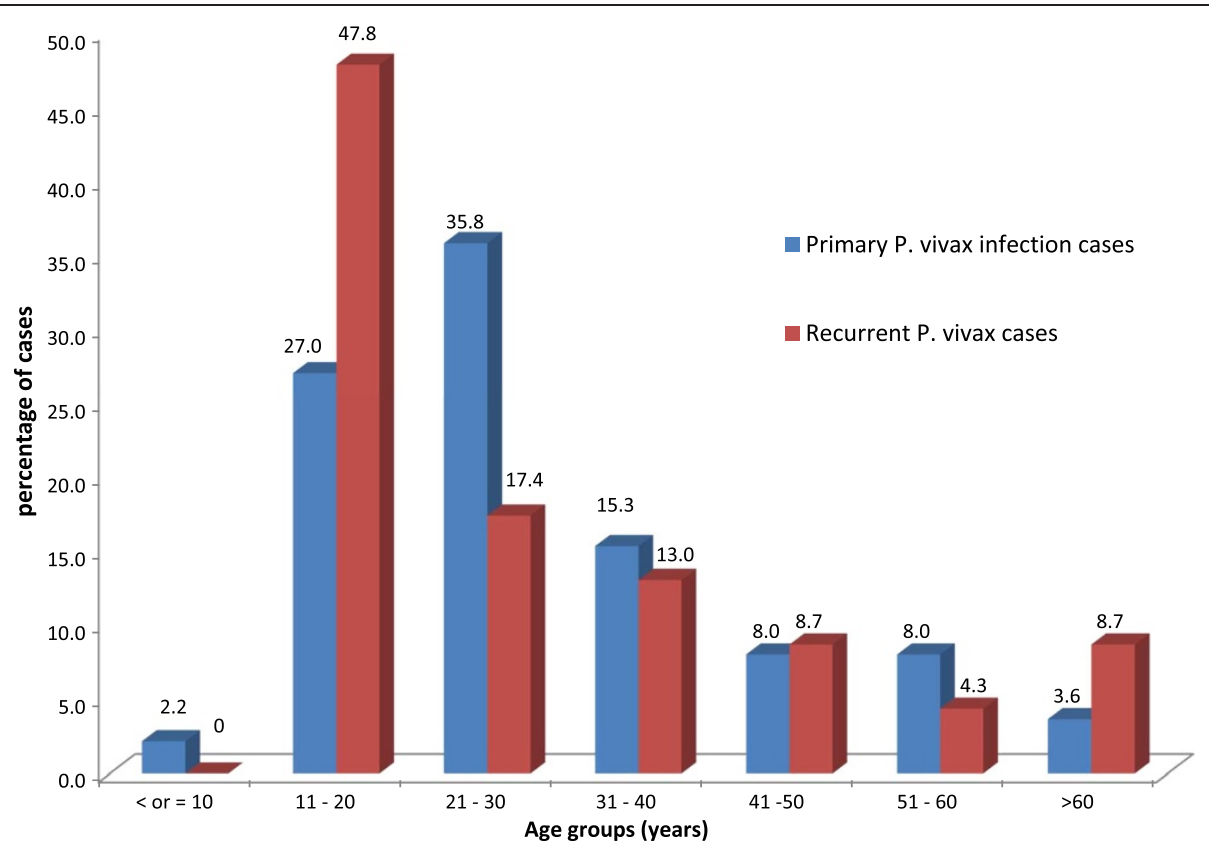

Figure 1 Percentage distribution of primary and recurrent infection cases of Plasmodium vivax among different age groups.

\section{Discussion}

It has been proposed that in endemic areas, a large proportion of indigenous population harbours latent hypnozoite forms of $P$. vivax, which can be activated by a systemic illness such as vivax or falciparum malaria. This is the reason for observed higher rates of relapse in people living in endemic areas especially in the pockets infiltrated with both of these malarial species [19]. The relapse rate of $P$. vivax varies considerably across various geographic regions. It also depends on immunity of the subjects to the disease $[19,20]$. Such relapses pose significant hurdles in an effective control of malaria, particularly for endemic countries like Nepal. However, in context of Nepal, negligible research has been conducted addressing such problems.

Since the two districts chosen for this study had high incidence of $P$. vivax transmission, higher probability of renewed infection among the enrolled cases could be

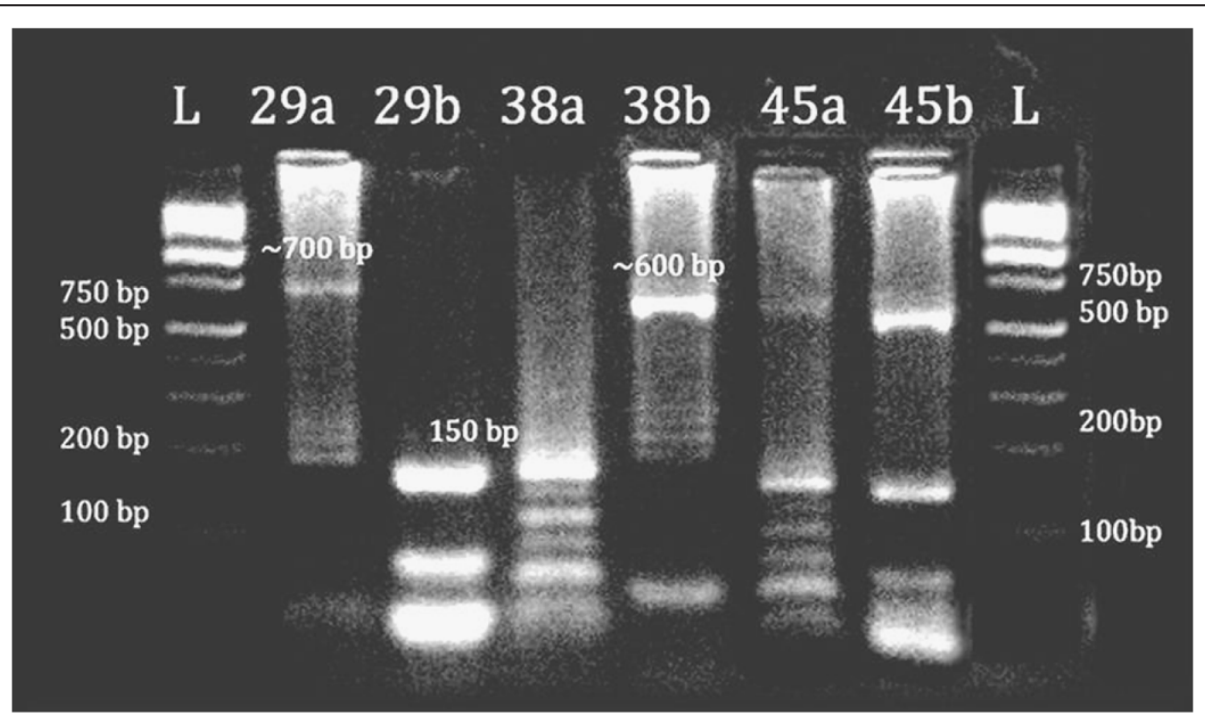

Figure 2 Gel picture of PCR RFLP-based Pvcsp genotyping of Plasmodium vivax for samples 29, 38 and 45; a and b are Alul and BstNI digestion products for each samples. Samples 29 and 38 each were digested by BstNI and Alul only, respectively, suggesting them to be of VK247 and VK210 type, respectively. Sample 45 was digested by both Alul and BstNI, suggesting it to be a mixed infection. 
expected at any time after completion of the chloroquine therapy in a developing country settings. Due to the nature of the study, re-infections could not be differentiated from relapses in this study and as such all recurrences were unequivocally considered as either relapse or re-infection. However, because primaquine was excluded initially for the treatment of $P$. vivax confirmed enrolled cases, it is highly probable that majority of recurrences were due to relapses.

In this study, a stringent follow up schedule had been practiced ensuring an absolute adherence to chloroquine treatment. Further, all study subjects were observed to respond well to the therapy thereby excluding any incidences of treatment failure. Moreover because all first time reported recurrences occurred after 28 days of primary detection and completion of standard chloroquine therapy, the possibility of recrudescence could be excluded in this study.

During six months' follow-up, a relapse/re-infection rate of $17 \%$ was detected. Variable recurrence rates of $P$. vivax has been recorded across the globe. In India, prospective studies carried out over the past 25 years have recorded post-chloroquine anti-malarial treatment recurrence rates to vary between $8.6 \%$ (Orissa), 8.9\% (Madhya Pradesh) [19], 12.6\% (Mumbai) [21] and 40\% (Delhi) [22]. Variable latency period among $P$. vivax phenotypes has been described $[19,23]$. A study in Delhi, India has observed a distinct rise in percentage of relapse cases as the follow-up period increased from one year (23.3\%) to five years (44.3\%) [22]. These findings suggest that determination of an actual relapse rate relies greatly on the duration of follow up. Taking this into consideration, for the follow-up period being less than a year, the relapse/re-infection rate of $17 \%$ observed in this study might probably be underestimated. Further, because there might possibly be many asymptomatic self- limiting relapse/re-infection cases that might have gone unreported and thus failed being recaptured, the true relapse/re-infection rate might have been higher than observed here.

A high percentage of relapse/reinfection was recorded among young people of age group 11 to 20 years which appeared to decrease with increasing age. This corroborates with literature findings that some degree of immunity is gained by early adulthood in indigenous population living in endemic areas, thereby reducing the number of relapses in increasing age groups [19].

In this study, a 14-day standard primaquine therapy was prescribed for all confirmed recurrence cases. However, many cases repeatedly suffered further episodes of recurrences, ranging from twice to as many as five times within a half-year period from primary infection. This suggested that the prescribed primaquine regimen as per the WHO recommendations [24] possibly was not absolutely efficient for preventing all relapses. This kind of therapeutic response variability and inadequacy has also been observed in many endemic regions $[20,25,26]$. However, it must be pointed out that, since the primaquine treatment provided to study subjects was an unmonitored 14-day course, an absolute compliance cannot be assured. Further, many of the recurrences might have been due to the renewed infection by blood stage parasites, against which the primaquine has reduced effect.

Regarding the circumsporozoite genotyping, VK210 genotype was found to be the most predominant genotype constituting $95 \%$ of parasite isolates. Though global prevalence of individual genotypes varies geographically, such prepotency of the VK210 genotype of $P$. vivax has been a common worldwide occurrence $[27,28]$. A similar study carried out in Pakistan showed results almost identical to this study - reporting isolation of $95.7 \%$ of VK210, 2.7\% of VK247 and 1.6\% of mixed genotypes. Such VK210 predominance has been reported in other malaria-endemic countries such as Myanmar (66\%), Thailand (77\%), Brazil (86\%), Kolkata (India) (99.3\%) Azerbaijan (100\%) and Honduras (100\%) [5,8,13,29-31]. This is in contrast to the findings of some studies reporting the predominance of VK247 genotype [32-34]. Such differences in prevalence of a different variant of parasite could be due to the predominance of different species and strain of Anopheles mosquito vector that is more susceptible to VK247 genotype as mentioned in several studies [14]. One study in southern Mexico [35] showed that Anopheles albimanus was more susceptible to infections by the VK210 subtype, while Anopheles pseudopunctipennis was more susceptible to VK247. However, in context of Nepal, out of 42 Anopheles species found, only three species, Anopheles fluviatilis, Anopheles maculates and Anopheles annularis have been identified as vectors of malaria [2]. This suggests that there might exist a unique dynamic interaction among existing $P$. vivax genotypes and Nepali strains of Anopheles vectors, thereby warranting further studies to verify this hypothesis.

Allelic variation of each of VK210 and VK247 based on number of repeats of central motif of Pvcsp gene and thus differences in size of PCR products could not be detected as previously observed [11,25] either because the $3 \%$ agarose gel was not sufficient enough to resolve the existing fragment length variations, or isolates in this study lacked this variation. Further, PCR-RFLP analysis of the isolates based on pre- and post repeats adjoining the central repeat region could not be determined when restriction-digested products were run in 3\% agarose gel probably because of the same above reasons. Use of capillary electrophoresis might have provided enough resolution to identify these minor fragment length variations.

\section{Conclusion}

In conclusion, $P$. vivax relapse/re-infection rate of $17 \%$ was observed during a brief follow up of six months, 
suggesting that the actual rate could be even higher provided the follow up were to extend. This contributes a significant hurdle in effective control of malaria in Nepal and challenges its ambitious goal to see a malaria-free country by 2026 .

Since this is the first-ever Pvcsp marker-based genotyping study carried out in Nepal, predominance of VK210 genotype can be considered as a primary information on Pvcsp genotype for Nepal. Further, as this study involved only two out of 65 malaria-endemic districts of Nepal, a larger representative study is warranted to provide further evidence on the type(s) and distribution of the prevailing Pvcsp genotypes of $P$. vivax.

\section{Abbreviations}

PCR: Polymerase chain reaction; Pvcsp: Plasmodium vivax circumsporozoite protein; RFLP: Restriction fragment length polymorphism.

\section{Competing interests}

The authors declared that they have no competing interests.

\section{Authors' contributions}

SM: all laboratory procedures including development of manuscript; CLB: Initiated initiated research as the Head of NHRC, the funding body and also supported MS preparation; UG: all fieldwork leading to collection of samples, and help in writing parts of manuscript; DK: supported laboratory work, and manuscript preparation; SPS: advisory role in manuscript preparation and field research; SMD: coordinated research and manuscript preparation. All authors read and approved the final manuscript.

\section{Acknowledgements}

We would like to acknowledge Nepal Health Research Council (NHRC) for initiating this research and providing samples. We thank all field researchers in this study as well as laboratory personnel of CMDN/INPL (Kathmandu) for helping with the field and laboratory work.

\section{Author details}

${ }^{1}$ Center for Molecular Dynamics Nepal, 5th Floor Swaraj Sadan, Prasuti Griha Marg, Thapathali-11, Kathmandu, Nepal. ${ }^{2}$ Nepal Health Research Council, Ministry of Health Complex, Ramshahpath, Kathmandu, Nepal.

\section{Received: 2 May 2013 Accepted: 18 August 2013}

Published: 16 September 2013

\section{References}

1. Ministry of Health, Nepal: Annual Report 2010/2011. Kathmandu: Department of Health Services; 2011.

2. Ministry of Health, Nepal: Nepal Malaria Strategic Plan 2011-2016 (Revised Version). Kathmandu, Nepal: Department of Health Services, Epidemiology \& Disease Control Division Teku; 2011

3. Adhikari M, Ranjitkar S, Schousboe ML, Alifrangis M, Imwong M, Bhatta DR, Banjara MR: Genetic diversity of Plasmodium vivax merozoite surface protein-3alpha (Pvmsp-3alpha) gene in Jhapa District of Nepal. Southeast Asian J Trop Med Public Health 2012, 43:280-286.

4. Banjara MR, Sirawaraporn W, Petmitr S, Imwong M, Joshi AB, Chavalitshewinkoon-Petmitr P: Characteristics and risk factors of Plasmodium falciparum malaria in Eastern and Central Nepal. Kathmandu Univ Med J (KUMJ) 2009, 7:378-382.

5. Kim TS, Kim HH, Lee SS, Na BK, Lin K, Cho SH, Kang YJ, Kim DK, Sohn Y, Kim H, Lee HW: Prevalence of Plasmodium vivax VK210 and VK247 subtype in Myanmar. Malar J 2010, 9:195.

6. Kirchgatter K, del Portillo HA: Molecular analysis of Plasmodium vivax relapses using the MSP1molecule as a genetic marker. J Infect Dis 1998, 177:511-515.

7. Mahajan RC, Farooq U, Dubey ML, Malla N: Genetic polymorphism in Plasmodium falciparum vaccine candidate antigens. Indian J Pathol Microbiol 2005, 48:429-438.
8. Lopez AC, Ortiz A, Coello J, Sosa-Ochoa W, Torres RE, Banegas El, Jovel I, Fontecha GA: Genetic diversity of Plasmodium vivax and Plasmodium falciparum in Honduras. Malar J 2012, 26:391.

9. Arnot DE, Barnwell JW, Tam JP, Nussenzweig V, Nussenzweig RS. Circumsporozoite protein of Plasmodium vivax: gene cloning and characterization of the immonodominant epitope. Science 1985, 230:815-817.

10. Rosenberg R, Wirtz RA, Lanar DE, Sattabongkot J, Hall T, Waters AP, Prasittisuk C: Circumsporozoite protein heterogeneity in the human malaria parasite Plasmodium vivax. Science 1989, 245:973-976.

11. Qari SH, Goldman IF, Povoa MM, Oliveira S, Alpers MP, Lal AA: Wide distribution of the variant form of the human malaria parasite Plasmodium vivax. J Biol Chem 1991, 266:16297-16300.

12. Qari SH, Collins WE, Lobel HO, Taylor F, Lal AA: A study of polymorphism in the circumsporozoite protein of human malaria parasites. Am J Trop Med Hyg 1994, 50:45-51.

13. Machado RLD, Póvoa MM: Distribution of Plasmodium vivax variants (VK210, VK247 and P. vivax-like) in three endemic areas of Amazonian Brazil and their correlation with chloroquine-treatment. Trans $R$ Soc Trop Med Hyg 2000, 94:377-381.

14. Gonzalez-Ceron L, Rodríguez MH, Entel JC, Villarreal C, Kain KC, Hernandez JE: Differential susceptibilities of Anopheles albimanus and Anopheles pseudopunctipennis to infections with coindigenous Plasmodium vivax variants VK210 and VK247 in Southern Mexico. Infect Immun 1999, 67:410-412

15. Machado RLD, Figueriredo-Filho AF, Calvosa VSP, Nascimento JM, Póvoa MM: Correlation between Plasmodium vivax variants in Belém, Pará State, Brazil and symptoms and clearence of parasitemia. J Infect Dis 2003, 7:175-177.

16. Souza-Neiras WC, Storti-Melo LM, Cassiano GC, Couto VS, Couto AA, Soares IS: Plasmodium vivax circumsporozoite genotypes: a limited variation or new subspecies with major biological consequences? Malar J 2010, 9:178.

17. Snounou G, Viriyakosol S, Zhu XP, Jarra W, Pinheiro L, do Rosario VE, Thaithong S, Brown KN: High sensitivity of detection of human malaria parasites by the use of nested polymerase chain reaction. Mol Biochem Parasitol 1993, 61:315-320.

18. Imwong M, Pukrittayakamee $S$, Grüner AC, Rénia L, Letourneur F, Looareesuwan S, White NJ, Snounou G: Practical PCR genotyping protocols for Plasmodium vivax using Pvcs and Pvmsp1. Malar J 2005, 4:20.

19. White NJ: Determinants of relapse periodicity in Plasmodium vivax malaria. Malar J 2011, 10:297.

20. Kim JR, Nandy A, Maji AK, Addy M, Dondorp AM, Day NP, Pukrittayakamee S, White NJ, Imwong M: Genotyping of Plasmodium vivax reveals both short and long latency relapse patterns in Kolkata. PLoS One 2012, 7:e39645.

21. Gogtay NJ, Desai S, Kadam VS, Kamtekar KD, Dalvi SS, Kshirsagar NA: Relapse pattern of Plasmodium vivax in Mumbai: a study of 283 cases of vivax malaria. J Assoc Phys India 2000, 48:1085-1086.

22. Adak T, Sharma VP, Orlov VS: Studies on the Plasmodium vivax relapse pattern in Delhi, India. Am J Trop Med Hyg 1998, 59:175-179.

23. Adak T, Valecha N, Sharma VP: Plasmodium vivax polymorphism in a clinical drug trial. Clin Diagn Lab Immunol 2001, 8:891-894.

24. World Health Organization: Guidelines for the treatment of malaria. Second edition. 1211 Geneva 27, Switzerland: WHO Press, World Health Organization, 20, avenue Appi; 2010.

25. Goller JL, Jolley D, Ringwald P, Biggs BA: Regional differences in the response of Plasmodium vivax malaria to primaquine as anti-relapse therapy. Am J Trop Med Hyg 2007, 76:203-207.

26. Baird JK, Hoffman SL: Primaquine therapy for malaria. Clin Infect Dis 2004 39:1336-1345

27. Zakeri S, Raeisi A, Afsharpad M, Kakar Q, Ghasemi F, Atta H, Zamani G, Memon MS, Salehi M, Djadid ND: Molecular characterization of Plasmodium vivax clinical isolates in Pakistan and Iran using pvmsp-1, pvmsp-3alpha and pvcsp genes as molecular markers. Parasitol Int 2010, 59:15-21.

28. Bonilla JA, Validum L, Cummings R, Palmer CJ: Genetic diversity of Plasmodium vivax Pvcsp and Pvmsp1 in Guyana, South America. Am J Trop Med Hyg 2006, 75:830-835.

29. Kim JR, Imwong M, Nandy A, Chotivanich K, Nontprasert A, Tonomsing N, Maji A, Addy M, Day NP, White NJ, Pukrittayakamee S: Genetic diversity of Plasmodium vivax in Kolkata, India. Malar J 2006, 5:71.

30. Cui L, Mascorro CN, Fan Q, Rzomp KA, Khuntirat B, Zhou G, Chen H, Yan G, Sattabongkot J: Genetic diversity and multiple infections of Plasmodium vivax malaria in Western Thailand. Am J Trop Med Hyg 2003, 68:613-619. 
31. Leclerc MC, Menegon M, Cligny A, Noyer JL, Mammadov S, Aliyev N, Gasimov E, Majori G, Severini C: Genetic diversity of Plasmodium vivax isolates from Azerbaijan. Malar J 2004, 3:40.

32. Kain KC, Brown AE, Webster HK, Wirtz RA, Keystone JS, Rodrigues MH, Kinahan J, Rowland M, Lanar DE: Circumsporozoite genotyping of global isolates of Plasmodium vivax from dried blood specimens. J Clin Microbiol 1992, 30:1863-1866.

33. Burket TR, Wirtz RA, Paru R, Garner P, Alpers MP: The population dynamics in mosquitoes and humans of two Plasmodium vivax polymorphs distinguished by different circumsporozoite protein repeat regions. Am J Trop Med Hyg 1992, 47:778-786.

34. Gonzalez JM, Hurtado S, Arevalo-Herrera M, Herrera S: Variants of the Plasmodium vivax circumsporozoite protein (VK210 and VK247) in Colombian isolates. Mem Inst Oswaldo Cruz 2001, 96:709-712.

35. Rodriguez MH, Gonzalez-Ceron L, Hernandez JE, Nettel JA, Villarreal C, Kain KC, Wirtz RA: Different prevalence of Plasmodium vivax phenotypes VK210 and VK247 associated with distribution of Anopheles albimanus and Anopheles psedopunctipennis in Mexico. Am J Trop Med Hyg 2000, 62:122-127.

doi:10.1186/1475-2875-12-324

Cite this article as: Manandhar et al:: A study on relapse/re-infection rate of Plasmodium vivax malaria and identification of the predominant genotypes of $P$. vivax in two endemic districts of Nepal. Malaria Journal 2013 12:324

\section{Submit your next manuscript to BioMed Central and take full advantage of:}

- Convenient online submission

- Thorough peer review

- No space constraints or color figure charges

- Immediate publication on acceptance

- Inclusion in PubMed, CAS, Scopus and Google Scholar

- Research which is freely available for redistribution 